\title{
VISIBLE LIGHT INDUCED PHOTOCATALYTIC DEGRADATION OF MALACHITE GREEN USING NANOSIZED BARIUM CHROMATE
}

\author{
Dinesh I. Prajapati1", Hari Shankar Sharma ${ }^{2}$ and Rakshit Ameta ${ }^{3}$ \\ ${ }^{1}$ Department of Chemistry, M. G. Science Institute, Ahmedabad-380009 (Guj.) India \\ ${ }^{2}$ Department of Chemistry, Govt. College, Kota-324001 (Raj.) India \\ ${ }^{3}$ Department of Chemistry, PAHER University, Udaipur-313001 (Raj.) India \\ "E-mail: diprajapatishyam@yahoo.in
}

\begin{abstract}
The photocatalytic degradation of malachite green was carried out in presence of nanosized barium chromate semiconducting powder used as a photocatalyst. The nanophotocatalyst was prepared by precipitation method and further characterized by XRD, SEM-EDS and FT-IR. The progress of the reaction was monitored spectrophotometrically. A tentative mechanism has been proposed where hydroxyl radical has been reported as an oxidizing agent for the photocatalytic degradation of the dye molecules. Some physicochemical parameters were studied, which also supported the mineralization of the dye solution.

Keywords: Photocatalytic degradation, Photocatalyst, Malachite green, Barium chromate.
\end{abstract}

(C) RASĀYAN. All rights reserved

\section{INTRODUCTION}

Water pollution is one of the world's most burning issues of today. The different industries produced a huge amount of wastewater in developing countries. The release of dyes from different dying industries into the aquatic system creates a large amount of water pollution. The colored wastewaters containing dye pollutants create many environmental and health hazards. Different methods have been used for the removal of dyes from wastewater like chemical, physical and biological methods, but each method has its own advantages and disadvantages. Photocatalysis method may play an important role to solve this problem. It is also an eco-friendly and low-cost method to remove dyes from wastewater. Soltaninezhad and Aminifar ${ }^{1}$ synthesized $\mathrm{ZnO}$ nanocrystalline photocatalyst and examined the photocatalytic activity of as-synthesized samples for the photodegradation of methylene blue while photodegradation of naphthol green $\mathrm{B}$ has been carried out by Ameta et al. ${ }^{2}$ using antimony trisulphide semiconductor. Houas et al. ${ }^{3}$ used $\mathrm{TiO}_{2} / \mathrm{UV}$-based photocatalyst to study the photocatalytic degradation pathway of methylene blue in aqueous solution whereas photocatalytic degradation of an azo dye acid red 27 was studied by Shanthi and Kuzhalosai ${ }^{4}$ using nano $\mathrm{ZnO}$ photocatalyst. $\mathrm{CdSe}-\mathrm{TiO}_{2}$ photocatalyst was synthesized by Lim et al. ${ }^{5}$ using a facile solvothermal method and used for photocatalytic degradation of methylene blue under UV and visible light. Movahedi et al. ${ }^{6}$ compared the photocatalytic efficiency of $\mathrm{ZnO}$ and $\mathrm{TiO}_{2}$ by photocatalytic bleaching of congo red dye.

Trabelsi et al. $^{7}$ carried out the photocatalytic degradation of malachite green in a photoreactor using $\mathrm{TiO}_{2} /$ cellulosic fibre as photocatalyst whereas $\mathrm{CdIn}_{2} \mathrm{~S}_{4}$ microspheres were synthesized by Xin et al. ${ }^{8}$ using a facile hydrothermal method at different temperatures ranging from 120 to $200^{\circ} \mathrm{C}$ and the photocatalytic activity of as-prepared $\mathrm{CdIn}_{2} \mathrm{~S}_{4}$ products was examined on photodegradation of methyl orange under visible light irradiation. Abdollahi et al. ${ }^{9}$ investigated the photocatalytic degradation of p-cresol by $\mathrm{ZnO}$ under UV irradiation while Yang et al. ${ }^{10}$ synthesized $\mathrm{H}_{3} \mathrm{PW}_{12} \mathrm{O}_{40} / \mathrm{SiO}_{2}$ photocatalyst using a sol-gel method and sensitized by $\mathrm{H}_{2} \mathrm{O}_{2}$ and the photocatalytic degradation of rhodamine $\mathrm{B}$ were studied using the as-prepared sample in presence of simulated natural light irradiation.

Rasayan J. Chem., 11(3), 1311-1319(2018)

http://dx.doi.org/10.31788/RJC.2018.1132071

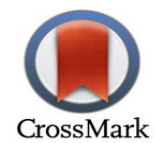


Kamel et $a l^{11}$ prepared porous $\mathrm{MgO}$ powder and tested for the decolorization of reactive orange 5 dye from aqueous solution in presence of $\mathrm{H}_{2} \mathrm{O}_{2}$ under $\mathrm{UV}$ radiation while Rose et al. ${ }^{12}$ synthesized lanthanum chromium oxide using co-precipitation method and proper heating cycles and the as-synthesized catalyst was used for photocatalytic degradation of azure-B.

The photocatalytic mineralization of phenol has been carried out by Zhang et al. ${ }^{13}$ in presence of $\mathrm{BiPO}_{4}$ photocatalyst under UV irradiation whereas Nihalani and co-workers ${ }^{14}$ used a new nanosized photocatalyst $\mathrm{BaO}_{3} \mathrm{TiO} . \mathrm{SrO}_{3} \mathrm{TiO}$ for the photocatalytic degradation of commercially used dyes (malachite green, crystal violet) and eosin yellow respectively. $\mathrm{Hu}$ and $\mathrm{Meng}^{15}$ synthesized $\mathrm{MoS}_{2} / \mathrm{TiO}_{2}$ nanocomposite by a chemical method and characterized by EDS spectrum and HRTEM and the photocatalytic activity of as-synthesized $\mathrm{MoS}_{2} / \mathrm{TiO}_{2}$ nanocomposite was tested on the degradation of malachite green. $\mathrm{Ag}_{3} \mathrm{PO}_{4}$ nanoparticles/ $/ \mathrm{TiO}_{2}$ nanobelts heterostructures were synthesized by Liu et al. ${ }^{16}$ using co-precipitation method and the photocatalytic degradation of methyl orange was carried out using $\mathrm{Ag}_{3} \mathrm{PO}_{4} / \mathrm{TiO}_{2}$ under UV irradiation while Gopalappa et al. ${ }^{17}$ prepared $\mathrm{CaZnO}_{2}$ nanoparticles using solution combustion method and characterized by XRD and SEM. The photocatalytic decolorization of azo dye acid orange 7 (AO7) was investigated using as-synthesized powder under sunlight. Anasane and Ameta ${ }^{18}$ reported morphologies of nanostructured bismuth sulphide and Mn (II) doped bismuth sulphide nanoparticles and decolorization of methyl violet using as prepared doped bismuth sulphide while Ashok et al. ${ }^{19}$ reported hydrothermal synthesis of ultraviolet-visible light responsive ruthenium doped titania (RuXTi1-XO2) nanosheet and also investigated its effect on photocatalytic degradation of reactive red dyes. In the present study, nanosized barium chromate has been prepared and it was further used to investigate the photocatalytic degradation of malachite green. It has been observed that due to its yellow color, it was an efficient photocatalyst in the visible region.

\section{Materials and Methods}

\section{EXPERIMENTAL}

$\mathrm{K}_{2} \mathrm{CrO}_{4}, \mathrm{BaCl}_{2}$, Malachite green, $\mathrm{NaOH}$ and $\mathrm{H}_{2} \mathrm{SO}_{4}$ (Himedia) were used as received.

The molecular formula of malachite green is $\mathrm{C}_{23} \mathrm{H}_{25} \mathrm{ClN}_{2}$ and its molecular weight is $364.91 \mathrm{~g} \mathrm{~mol}^{-1}$. Its chemical structure is given in Figure 1.

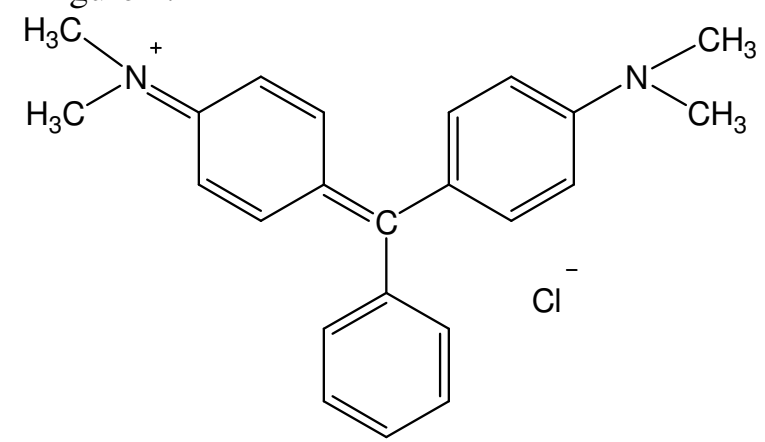

Fig. 1:- Chemical Structure of Malachite Green

\section{Preparation of Nano-sized Barium Chromate Semiconductor}

Nanosized barium chromate was prepared using $\mathrm{K}_{2} \mathrm{CrO}_{4}$ and $\mathrm{BaCl}_{2}$ through precipitation method. $100 \mathrm{~mL}$ $5 \%$ aqueous solution of $\mathrm{BaCl}_{2}$ was mixed with $100 \mathrm{~mL} 5 \%$ aqueous solution of $\mathrm{K}_{2} \mathrm{CrO}_{4}$ with constant stirring. The resulting precipitate of $\mathrm{BaCrO}_{4}$ was allowed to settle down. The product was filtered, washed with doubly distilled water several times and dried at $60^{\circ} \mathrm{C}$ in an oven.

A stock solution of malachite green having the concentration of $1.0 \times 10^{-3} \mathrm{M}$ was prepared in double distilled water. This stock solution was further diluted as and when required. The absorbance of the malachite green solution was measured with the help of a spectrophotometer (Systronics Model 106) at $\lambda_{\max }=620 \mathrm{~nm}$. In the present work, the malachite green dye has been used as a model system to study the photocatalytic activity of barium chromate. The results of some control experiments showed that degradation of malachite green requires the presence of both light and the semiconductor $\mathrm{BaCrO}_{4}$ and therefore, this reaction is a photocatalytic reaction in nature. 


\section{Characterization}

\section{XRD}

X-ray diffraction studies of the sample were conducted using PANalytical, Singapore make, XPERT-PRO model with $\mathrm{Cu} \mathrm{K}_{\alpha}$ radiation $\left(\lambda=1.54060 \mathrm{~A}^{\circ}, 2 \Theta=10\right.$ to $80^{\circ}$ with generator setting $\left.40 \mathrm{~mA}, 45 \mathrm{kV}\right)$. Diffraction pattern was taken over the $2 \theta$ range $10^{\circ}-70^{\circ}$. Figure- 2 shows the XRD pattern of synthesized nano-particles of $\mathrm{BaCrO}_{4}$. It was observed that all the diffraction peaks were similar to that of orthorhombic phase of $\mathrm{BaCrO}_{4}$ (JCPDS-15-376, lattice constants, $\mathrm{a}=8.2026^{\circ}, \mathrm{b}=8.2026^{\circ}, \mathrm{c}=13.6302^{\circ}$ A).

The particle size of the synthesized barium chromate was calculated using Sherrer formula (Eq.-1) and it was found as $14.71 \mathrm{~nm}$.

$$
D=\frac{K \lambda}{\beta \cos \theta}
$$

Where $\mathrm{K}$ is a constant, which depends on the shape of the crystal and its value is 0.9 assuming spherical shape; $\lambda$ is the wavelength; $\mathrm{D}$ is the crystallite size; $\beta$ is full width of half maxima (FWHM) value (calculated for the XRD pattern) and $\theta$ is Bragg's angle.

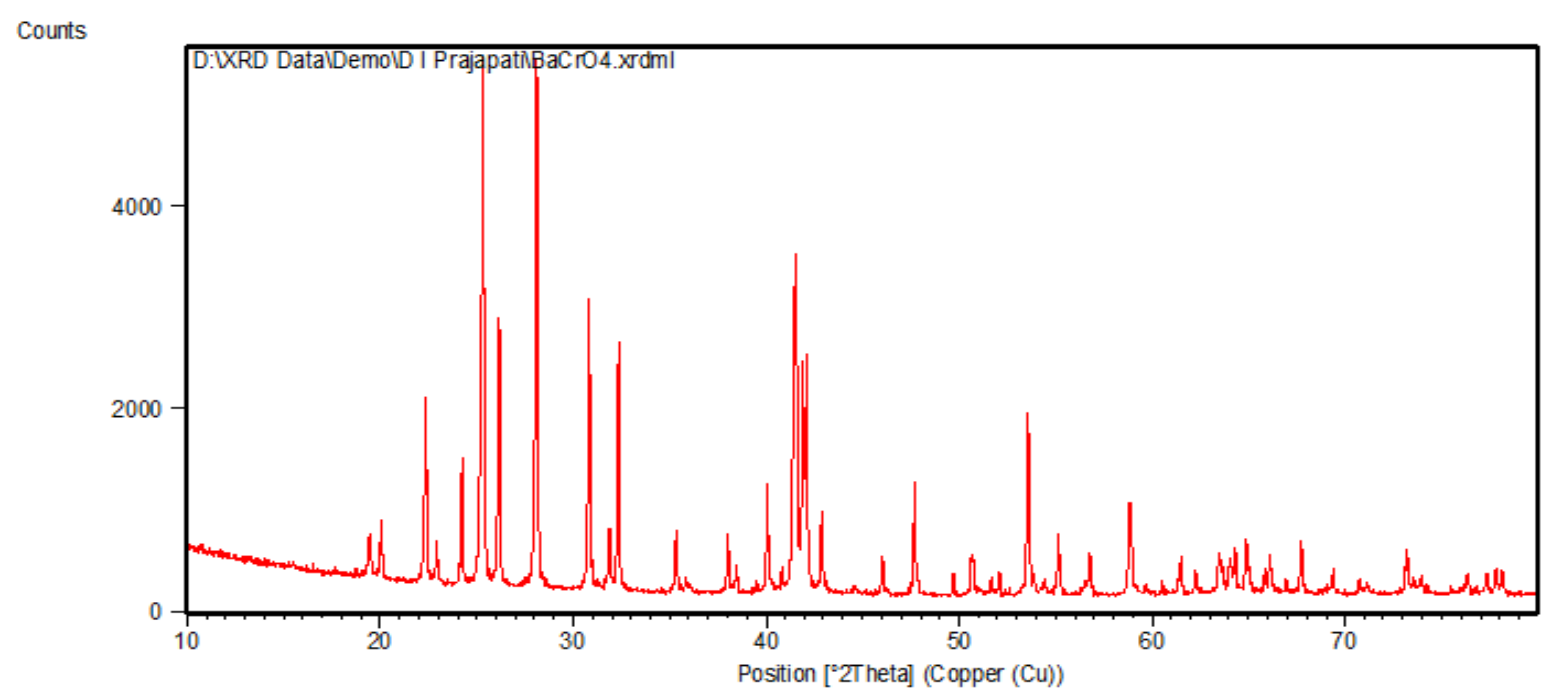

Fig. 2:- XRD of Barium Chromate Semiconductor

\section{SEM-EDS Analysis}

Scanning electron microscopy studies of the sample were conducted using JEOL, Japan make, 5610LV model. It was operated at $15 \mathrm{kV}$. SEM-EDS of barium chromate is given in Fig.-3.

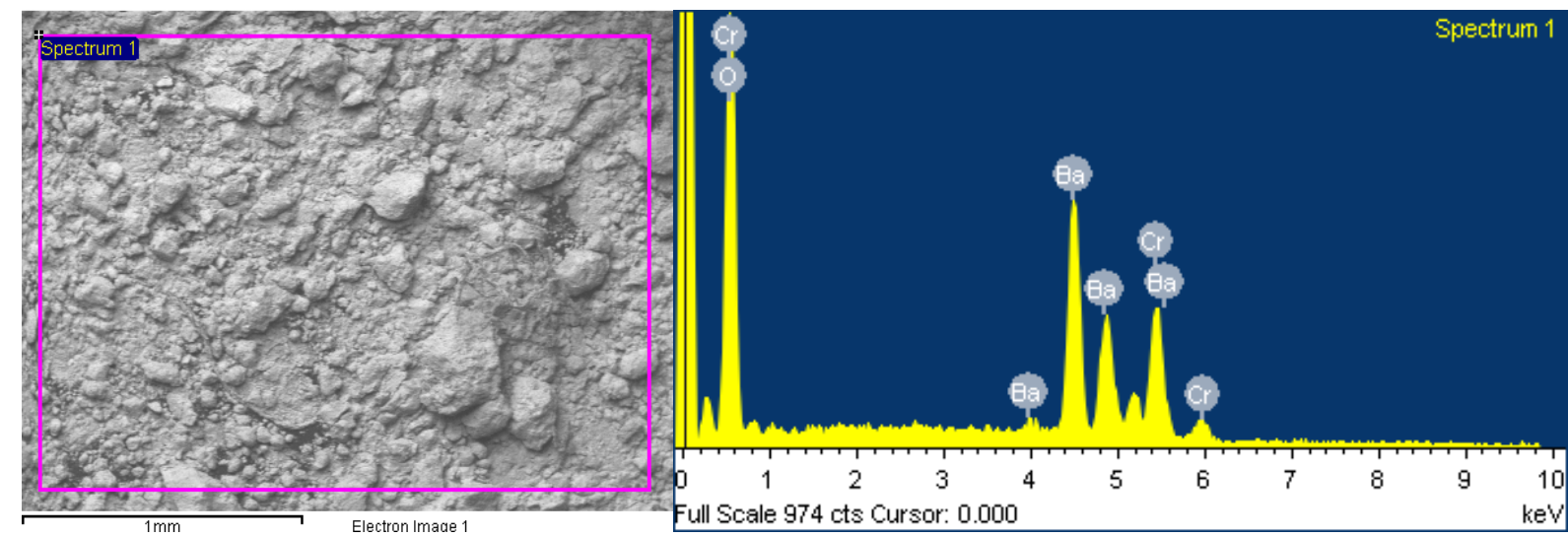

Fig. 3:- SEM-EDS of Barium Chromate 
RASĀYAN J. Chem.

Vol. 11 | No. 3 |1311 - 1319 | July - September | 2018

SEM of the synthesized semiconductor indicates that particles are unevenly distributed in size and EDS gives clearly that the catalyst contains only barium, chromium and oxygen only and it does not have any impurity.

\section{FT-IR}

Fourier transform-infrared (FT-IR) spectroscopy of the sample was carried out on a Shimadzu, IR Affinity, using $\mathrm{KBr}$ disk method and it showed in Fig.-4.

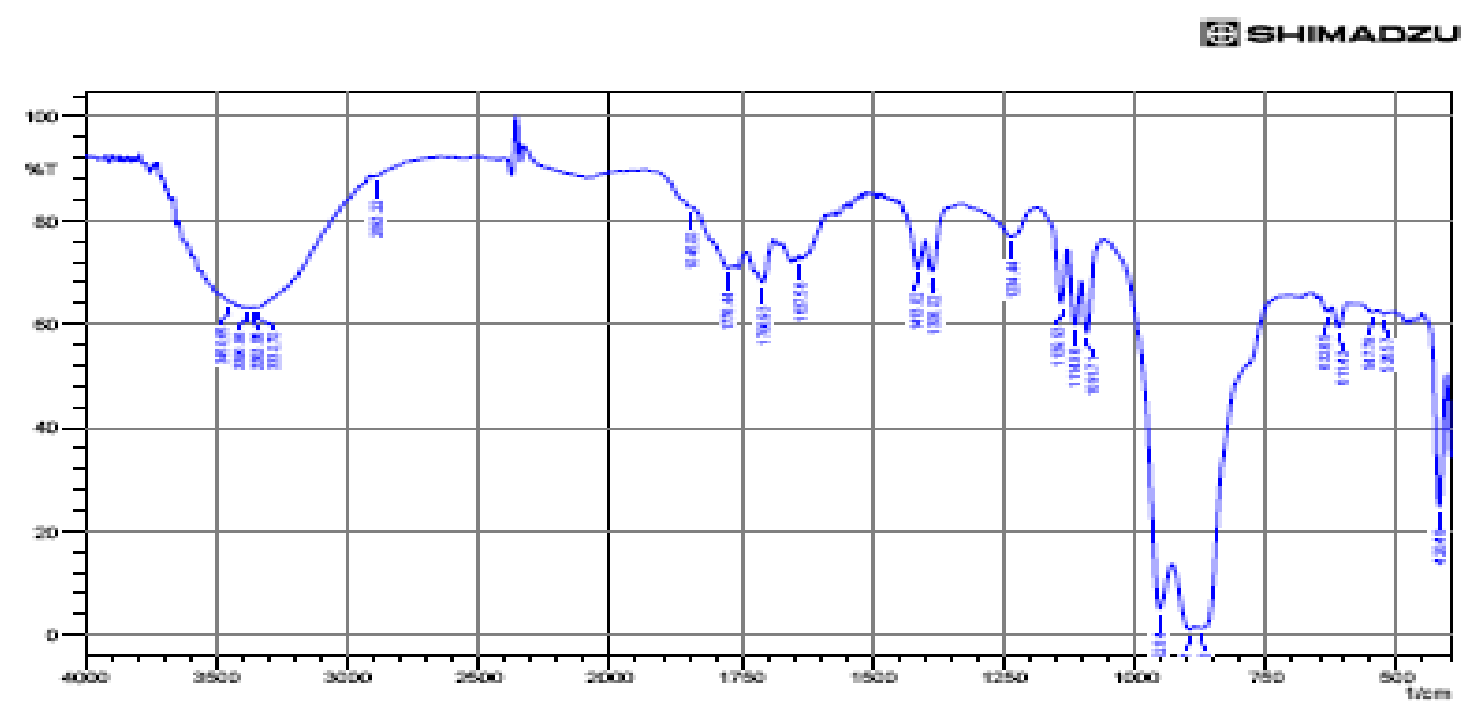

Fig.-4: FT-IR of Barium Chromate

FT-IR spectra of $\mathrm{BaCrO}_{4}$ nano-particles shows the characteristic absorption bands of chromate group located at 875,894 and $952 \mathrm{~cm}^{-1}$.

\section{RESULTS AND DISCUSSION}

A solution of $1.1 \times 10^{-4} \mathrm{M}$ of malachite green was prepared in double distilled water and $0.10 \mathrm{~g}$ of $\mathrm{BaCrO}_{4}$ was added to it. The $\mathrm{pH}$ of the reaction mixture was adjusted to 9.0 with the help of previously standardized sodium hydroxide and sulphuric acid solutions. Then the solution was exposed to the light of a $200 \mathrm{~W}$ tungsten lamp. An aliquot of $2.0 \mathrm{~mL}$ was taken out from the reaction mixture and its absorbance was measured at $620 \mathrm{~nm}$ at regular time intervals.

Table-1: A typical run $\mathrm{pH}=9.0,[$ Malachite green $]=1.1 \times 10^{-4} \mathrm{M}, \mathrm{BaCrO}_{4}=0.10 \mathrm{~g}$, Light intensity $=60.0 \mathrm{mWcm}^{-2}$

\begin{tabular}{c|c|c}
\hline Time (min.) & Absorbance (A) & $1+\log \mathrm{A}$ \\
\hline 0.0 & 0.72 & 0.8573 \\
\hline 5.0 & 0.62 & 0.7924 \\
\hline 10.0 & 0.52 & 0.7160 \\
\hline 15.0 & 0.45 & 0.6532 \\
\hline 20.0 & 0.38 & 0.5798 \\
\hline 25.0 & 0.32 & 0.5051 \\
\hline 30.0 & 0.27 & 0.4314 \\
\hline 35.0 & 0.23 & 0.3617 \\
\hline 40.0 & 0.20 & 0.3010 \\
\hline 45.0 & 0.17 & 0.2304 \\
\hline 50.0 & 0.14 & 0.1461 \\
\hline Rate constant $(\mathrm{k})=5.50 \times 10^{-4} \mathrm{sec}^{-1}$ & \\
\hline
\end{tabular}


It was observed that there was a decrease in the absorbance of the malachite green solution with increasing time of exposure. The typical run for the photocatalytic degradation of malachite green in presence of barium chromate semiconductor has been presented in Table-1 and graphically represented in Fig.-5.

A linear plot between $1+\log$ A against time was obtained, which indicates that the photocatalytic degradation of malachite green follows pseudo-first order kinetics. The rate constant of this reaction was measured with the expression; $\mathrm{k}=2.303 \times$ slope. Some of the factor affecting the rate of the reaction was studied to obtain optimum conditions for photocatalytic degradation of the dye.

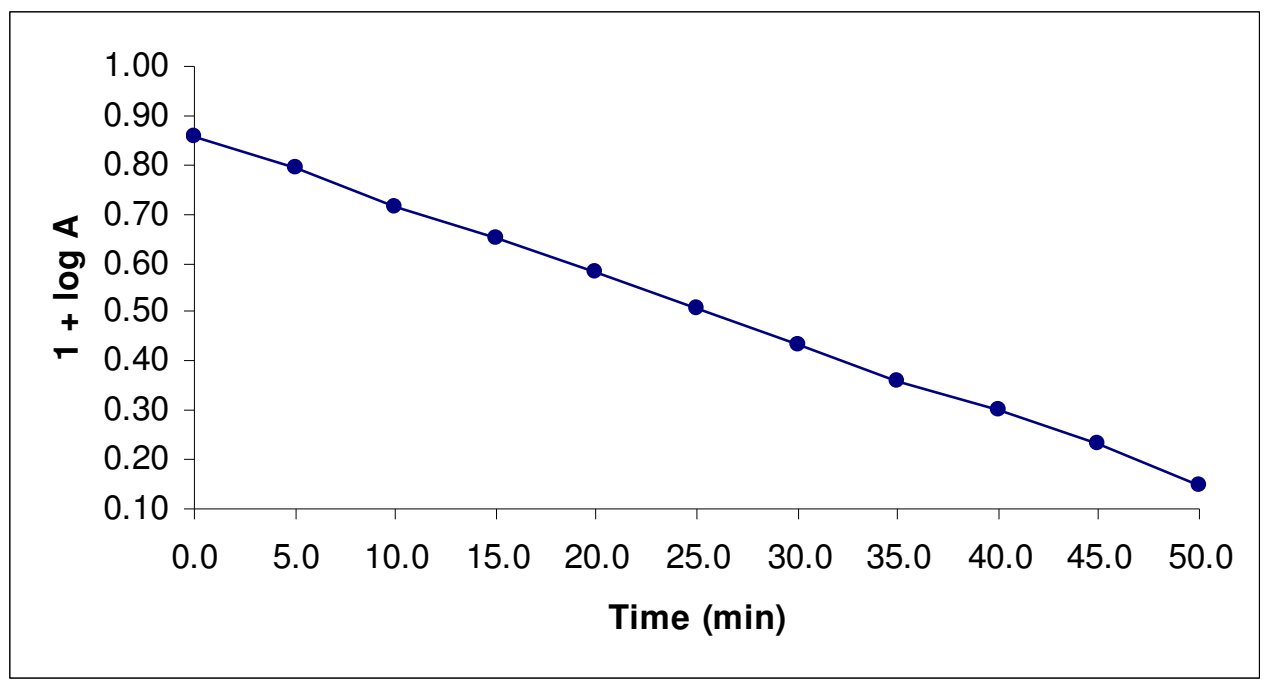

\section{Effect of $\mathrm{pH}$}

Fig.-5: Typical Run for Degradation of Malachite Green

The $\mathrm{pH}$ of the solution may affect the degradation of malachite green. The effect of $\mathrm{pH}$ on the rate of degradation of malachite green was studied in the $\mathrm{pH}$ range of $5.0-10.0$. The results are summarized in Table-2.

Table-2:Effect of $\mathrm{pH}$

$[$ Malachite green $]=1.1 \times 10^{-4} \mathrm{M}$, Light intensity $=60.0 \mathrm{mWcm}^{-2}, \mathrm{BaCrO}_{4}=0.10 \mathrm{~g}$

\begin{tabular}{c|c}
\hline $\mathrm{pH}$ & Rate Constant $(\mathrm{k}) \times 10^{4}\left(\mathrm{sec}^{-1}\right)$ \\
\hline 5.0 & 0.13 \\
\hline 5.5 & 0.19 \\
\hline 6.0 & 0.34 \\
\hline 6.5 & 0.81 \\
\hline 7.0 & 2.30 \\
\hline 7.5 & 3.11 \\
\hline 8.0 & 3.67 \\
\hline 8.5 & 4.33 \\
\hline 9.0 & 5.50 \\
\hline 9.5 & 4.57 \\
\hline 10.0 & 3.35 \\
\hline
\end{tabular}

It has been observed that there was an increase in the rate of photocatalytic degradation of malachite green with an increase in $\mathrm{pH}$ and it attained optimum value at $\mathrm{pH} 9.0$. On further increasing $\mathrm{pH}$, the rate of degradation was decreased. The increase in the rate of photocatalytic degradation may be due to more availability of the $\mathrm{OH}^{-}$ions at higher $\mathrm{pH}$ values. $\mathrm{OH}^{-}$ions will generate more ${ }^{\bullet} \mathrm{OH}$ radicals by combining with the holes $\left(\mathrm{h}^{+}\right)$of semiconductor and these ${ }^{\circ} \mathrm{OH}$ radicals are considered responsible for the photocatalytic degradation. But after a certain value of $\mathrm{pH}$ i.e. 9.0, a further increase in $\mathrm{pH}$ of the medium decreased the rate of photocatalytic degradation. It may be due to the fact that malachite green does not 
RASĀYAN J. Chem.

Vol. 11 | No. 3 |1311 - 1319 | July - September | 2018

remain in its cationic form due to a greater concentration of $\mathrm{OH}^{-}$ions and as such, the repulsion between the dye and negatively charged semiconductor surface increases. As a result, the reaction rate decreases.

\section{Effect of Malachite Green Concentration}

The effect of dye concentration on the rate of photocatalytic degradation was studied by taking different concentrations of malachite green. The results are summarized in table 3.

Table-3: Effect of Malachite Green Concentration $\mathrm{pH}=9.0, \mathrm{BaCrO}_{4}=0.10 \mathrm{~g}$, Light intensity: $60.0 \mathrm{mWcm}^{-2}$

\begin{tabular}{c|c}
$\mathrm{pH}=9.0, \mathrm{BaCrO}_{4}=0.10 \mathrm{~g}$, Light intensity: $60.0 \mathrm{mWcm}^{-2}$ \\
\hline$\left[\right.$ Malachite green $\times 10^{4} \mathrm{M}$ & Rate Constant $(\mathrm{k}) \times 10^{4}\left(\mathrm{sec}^{-1}\right)$ \\
\hline 0.8 & 2.75 \\
\hline 0.9 & 3.28 \\
\hline 1.0 & 4.26 \\
\hline 1.1 & 5.50 \\
\hline 1.2 & 4.44 \\
\hline 1.3 & 3.69 \\
\hline 1.4 & 3.20 \\
\hline
\end{tabular}

It was observed that the rate of photocatalytic degradation increased with increase in the concentration of malachite green up to $1.1 \times 10^{-4} \mathrm{M}$. This may be attributed to the fact that as the concentration of malachite green was increased, more dye molecules were available for excitation followed by intersystem crossing and energy transfer and hence, the rate of degradation was increased. There was a decrease in the rate of degradation with a further increase in the concentration above $1.1 \times 10^{-4} \mathrm{M}$. This may be attributed to the fact that the dye will start acting as a filter for the incident light and it will not permit the desired light intensity to reach the semiconducting particles, thus, decreasing the rate of photocatalytic degradation of the dye.

\section{Effect of Amount of Photocatalyst}

The amount of semiconductor may also affect the rate of degradation of dye and hence, different amounts of semiconductor barium chromate were taken. The results are summarized in Table 4.

Table-4: Effect of Amount of Photocatalyst

$$
\mathrm{pH}=9.0,[\text { Malachite green }]=1.1 \times 10^{-4} \mathrm{M}, \text { Light intensity }=60.0 \mathrm{mWcm}^{-2}
$$

\begin{tabular}{c|c}
\hline $\mathrm{BaCrO}_{4}(\mathrm{~g})$ & Rate Constant $(\mathrm{k}) \times 10^{4}\left(\mathrm{sec}^{-1}\right)$ \\
\hline 0.02 & 2.66 \\
\hline 0.04 & 3.16 \\
\hline 0.06 & 3.84 \\
\hline 0.08 & 4.42 \\
\hline 0.10 & 5.50 \\
\hline 0.12 & 5.48 \\
\hline 0.14 & 5.50 \\
\hline 0.16 & 5.48 \\
\hline
\end{tabular}

It was observed that there was an increase in the rate of photocatalytic degradation with an increase in the amount of semiconductor up to $0.10 \mathrm{~g}$, but after the amount $0.10 \mathrm{~g}$ of semiconductor, it becomes almost constant. This may be attributed to the fact that as the amount of semiconductor was increased, the exposed surface area of semiconductor also increased, but after a certain limit i.e. $0.10 \mathrm{~g}$, if the amount of semiconductor was further increased, then there will be no increase in the exposed surface area of the photocatalyst. It may be considered like a saturation point; above which, any increase in the amount of semiconductor had negligible or no effect on the rate of photocatalytic degradation of dye, as an increase 
RASĀYAN J. Chem.

Vol. 11 | No. 3 |1311 - 1319 | July - September | 2018

in the amount of semiconductor after this saturation point would only increase the thickness of the layer at the bottom of the reaction vessel. This was confirmed by taking reaction vessels of different dimensions. The saturation point shifted to the higher range for larger vessels, while the reverse was true for smaller vessels.

\section{Effect of Light Intensity}

The variation in light intensity may also affect the rate of photocatalytic degradation. Hence, the distance between the light source and the exposed surface area was varied. The intensity of light at each distance was measured using Suryamapi (CEL Model SM201). The results are reported in Table-5.

Table-5: Effect of Light Intensity

\begin{tabular}{c|c}
$\mathrm{pH}=9.0,[$ Malachite green $]=1.1 \times 10^{-4} \mathrm{M}, \mathrm{BaCrO}_{4}=0.10 \mathrm{~g}$ \\
\hline Light intensity $\left(\mathrm{mWcm}^{-2}\right)$ & Rate Constant $(\mathrm{k}) \times 10^{4}\left(\mathrm{sec}^{-1}\right)$ \\
\hline 20.0 & 2.29 \\
\hline 30.0 & 3.26 \\
\hline 40.0 & 4.26 \\
\hline 50.0 & 4.98 \\
\hline 60.0 & 5.50 \\
\hline 70.0 & 4.84 \\
\hline 80.0 & 4.39 \\
\hline
\end{tabular}

The results showed that degradation of dye was accelerated as the intensity of light was increased, because any increase in the light intensity will increase the number of photons striking per unit area of semiconductor powder. However, by increasing the intensity above $60.0 \mathrm{mWcm}^{-2}$, there was a little decrease in the rate. This may be due to some thermal reactions.

\section{Mechanism}

On the basis of the experimental observations, a tentative mechanism of photocatalytic degradation of malachite green has been proposed as follows:

Malachite green (MG) absorbs radiation of suitable wavelength giving rise to its excited first singlet state followed by intersystem crossing (ISC) to the triplet state. On the other hand, the semiconducting barium chromate also utilizes the incident light energy to excite its electron from the valence band to conducting band; thus, leaving behind a hole. This hole may abstract an electron from hydroxyl ions to generate hydroxyl radicals. These hydroxyl radicals will then oxidize the dye to its leuco form, which may ultimately degrade to harmless products.

$$
\begin{aligned}
& { }^{1} \mathrm{MG}_{\mathrm{o}} \longrightarrow{ }^{\mathrm{h} v} \longrightarrow{ }^{1} \mathrm{MG}_{1} \\
& { }^{1} \mathrm{MG}_{1} \longrightarrow{ }_{\mathrm{ISC}}^{\longrightarrow}{ }^{3} \mathrm{MG}_{1} \\
& \mathrm{SC} \stackrel{\mathrm{h} v}{\longrightarrow} \mathrm{e}^{-}(\mathrm{CB})+\mathrm{h}^{+}(\mathrm{VB}) \\
& \mathrm{h}^{+}+\mathrm{OH}^{-} \longrightarrow{ }^{\cdot} \mathrm{OH} \\
& { }^{3} \mathrm{MG}_{1}+{ }^{\cdot} \mathrm{OH} \longrightarrow \text { Leuco } \mathrm{MG} \\
& \text { Leuco } \mathrm{MG} \longrightarrow \text { Products }
\end{aligned}
$$

The participation of ${ }^{\bullet} \mathrm{OH}$ radicals as an active oxidizing species was confirmed by using hydroxyl radical scavengers (2-propanol), where the rate of degradation was drastically reduced.

Some of the physicochemical parameters were studied to confirm the mineralization of dye solution in harmless products so that it may be used for cleaning purpose after photocatalytic treatment.

$\mathrm{pH}$ of the dye solution was 4.45 before treatment and it was found almost neutral after photocatalytic degradation of the dye. TDS and conductance were also increased from 40 to $71 \mathrm{ppm}$ and 28 to $88 \mu \mathrm{S}$, 
respectively in treated water. Dissolved oxygen (DO) analysis measures the amount of gaseous oxygen dissolved in an aqueous solution and in the present case it was increased from 6.7 to $7.9 \mathrm{ppm}$. Enhancement in $\mathrm{pH}$, conductivity, TDS and DO confirms the mineralization of dye to a significant extent. The value of chemical oxygen demand (COD) shows the oxidizability of a substance and it is expressed as the equivalent amount in oxygen of an oxidizing reagent consumed by the substance under fixed laboratory conditions. The chemical oxygen demand of reaction mixture before and after treatment has been determined by redox method. The photodegradation efficiency of the catalyst was calculated from the following expression:

$$
\begin{aligned}
& \eta=\frac{\mathrm{COD}_{\text {before }}-\mathrm{COD}_{\text {after }}}{\mathrm{COD}_{\text {before }}} \times 100 \\
& \eta=\text { Photodegradation efficiency }(\%), \\
& \mathrm{COD}_{\text {before }}=\mathrm{COD} \text { of dye solution before illumination, and } \\
& \mathrm{COD}_{\text {after }}=\mathrm{COD} \text { of dye solution after illumination }
\end{aligned}
$$

In the present case, COD was decreased from 36 to $12 \mathrm{ppm}$, which is a notable change. The photodegradation efficiency after 4 hours of illumination has been found to be $73.22 \%$.

Biological Oxygen Demand (BOD) is a measure of the oxygen used by microorganisms to decompose waste. BOD of the dye solution before and after treatment was decreased from 6.2 to $1.5 \mathrm{ppm}$, which shows that photocatalytic treatment increases the biodegradability.

Table-6: A Comparative Study for Some Physico-Chemical Parameters of Aqueous Solution of Malachite Green (Before and After Treatment)

\begin{tabular}{c|c|c}
\hline Parameters & Before Treatment & After Treatment \\
\hline $\mathrm{pH}$ & 4.45 & 7.78 \\
\hline Conductance & $28.0 \mu \mathrm{S}$ & $88.0 \mu \mathrm{S}$ \\
\hline TDS & $40.0 \mathrm{ppm}$ & $71.0 \mathrm{ppm}$ \\
\hline DO & $6.7 \mathrm{ppm}$ & $7.9 \mathrm{ppm}$ \\
\hline COD & $54.9 \mathrm{ppm}$ & $14.7 \mathrm{ppm}$ \\
\hline BOD & $6.2 \mathrm{ppm}$ & $1.5 \mathrm{ppm}$ \\
\hline
\end{tabular}

\section{CONCLUSION}

Nanosized barium chromate photocatalyst was synthesized by precipitation method further characterized to know its morphology. It was used for the photocatalytic degradation of malachite green successfully. The results showed that dye was completely degraded using this photocatalyst and the use of the photocatalyst can be explored for the degradation of different pollutants.

\section{ACKNOWLEDGMENT}

The authors are thankful to Department of Chemistry, PAHER University, Udaipur (Raj.) and Department of Chemistry, M. G. Science Institute, Ahmedabad (Guj.) for providing necessary laboratory facilities.

\section{REFERENCES}

1. M. Soltaninezhad and A. Aminifar, Int. J. Nano Dim., 2(2), 137(2011).

2. R. Ameta, P.B. Punjabi and S.C. Ameta, J. Serbian Chem. Soc., 76, 1049(2011), DOI: 10.2298/JSC100425082A.

3. A. Houas, H. Lachheb, M. Ksibi, E. Elaloui, C. Guillard and J.M. Herrmann, Appl. Catal., B, 31, 145 (2001), DOI: 10.1016/S0926-3373(00)00276-9.

4. M. Shanthi and V. Kuzhalosai, Indian J. Chem. A, 51A, 428(2012).

5. C.S. Lim, M.L. Chen and W.C. Oh, Bull. Korean Chem. Soc., 32(5), 1657(2011), DOI: 10.5012/bkcs.2011.32.5.1657.

6. M. Movahedi, A.R. Mahjoub and S.J. Darzi, J. Iran. Chem. Soc., 6(3), 570(2009), DOI: 10.1007/BF03246536. 
7. H. Trabelsi, P. Atheba, G.K. Gbassi, M. Ksibi and P. Drogui, Int. J. Hazard. Mat., 1(1), 6(2012).

8. C.Z. Xin, R. Z. Yun, X.J. -Jing, X.G. Can and H.Y. Hui, Chinese J. Struct. Chem., 31(12), 1815 (2012).

9. Y.A. Abdollahi, A.H. Abdullah, Z. Zainal and N.A. Yusof, Int. J. Mol. Sci., 13, 302(2012), DOI: 10.3390/ijms13010302.

10. S. Yang, Y. Huang, Y. Wang, Y. Yang, M. Xu and G. Wang, Int. J. Photoenergy, DOI: 10.1155/2012/927132 (2012).

11. M.M. Kamel. H.M. Mashaly and F. Abdelghaffar, World Appl. Sci. J., 26(8), 1053(2013), DOI: 10.5829/idosi.wasj.2013.26.08.13546.

12. J. Rose, J. Ameta, P.B. Punjabi, V.K. Sharma and S.C. Ameta, Bull. Catal. Soc. India, 6, 110(2007).

13. Y. Zhang, R. Selvaraj, M. Sillanpaa, Y. Kim and C.W. Tai, Chem. Eng. J., 245, 117(2014), DOI: 10.1016/j.cej.2014.02.028.

14. S. Nihalani, A. Vijay, N. Tripathi and S. Bhardwaj, IOSR J. Appl. Chem., 2(5), 20(2012).

15. K.H. Hu and M. Meng, Asian J. Chem., 25(10), 5827(2013).

16. R. Liu, P. Hu and S. Chen, Appl. Surf. Sci., 258, 9805(2012), DOI: 10.1016/j.apsusc.2012.06.033.

17. H. Gopalappa, K. Yogendra and K.M. Mahadevan, Int. J. Res. Chem. Environ., 2(3), 39(2012).

18. N. Anasane and R. Ameta, Mat. Sci. Poland, 35, 6(2017), DOI: 10.1515/msp-2017-0032.

19. A. Ashok, K. Raman, S.A. Masilamani and R.S.C. Bose, Rasayan J. Chem., 11(1), 53(2018), DOI: 10.7324/RJC.2018.1111969.

[RJC-2071/2018] 